\title{
BMJ Open Does a complex intervention targeting communities, health facilities and district health managers increase the utilisation of community-based child health services? A before and after study in intervention and comparison areas of Ethiopia
}

Della Berhanu (D) , ${ }^{1,2}$ Yemisrach Behailu Okwaraji, ${ }^{1}$ Atkure Defar (D) , ${ }^{2,3}$ Abebe Bekele, ${ }^{2}$ Ephrem Tekle Lemango, ${ }^{4}$ Araya Abrha Medhanyie, ${ }^{5}$ Muluemebet Abera Wordofa, ${ }_{6}^{6}$ Mezgebu Yitayal, ${ }^{7}$ Fitsum W/Gebriel, ${ }^{8}$ Alem Desta, ${ }^{5}$ Fisseha Ashebir Gebregizabher, ${ }^{5,9}$ Dawit Wolde Daka (D) ,10 Alemayehu Hunduma, ${ }^{6,11}$ Habtamu Beyene,,${ }^{8,12}$ Tigist Getahun, ${ }^{13,14}$ Theodros Getachew, ${ }^{2,13}$ Amare Tariku Woldemariam, ${ }^{15}$ Desta Wolassa, ${ }^{2}$ Lars Åke Persson (1) ,1,2 Joanna Schellenberg ${ }^{1}$

To cite: Berhanu $D$, Okwaraji YB, Defar A, et al. Does a complex intervention targeting communities, health facilities and district health managers increase the utilisation of communitybased child health services? $A$ before and after study in intervention and comparison areas of Ethiopia. BMJ Open 2020;10:e040868. doi:10.1136/ bmjopen-2020-040868

- Prepublication history for this paper is available online. To view these files, please visit the journal online (http://dx.doi. org/10.1136/bmjopen-2020040868).

Received 27 May 2020 Revised 23 July 2020 Accepted 03 August 2020

Check for updates

(C) Author(s) (or their employer(s)) 2020. Re-use permitted under CC BY. Published by BMJ.

For numbered affiliations see end of article.

Correspondence to

Dr Della Berhanu;

Della.Berhanu@|shtm.ac.uk

\section{ABSTRACT}

Introduction Ethiopia successfully reduced mortality in children below 5 years of age during the past few decades, but the utilisation of child health services was still low. Optimising the Health Extension Programme was a 2year intervention in 26 districts, focusing on community engagement, capacity strengthening of primary care workers and reinforcement of district accountability of child health services. We report the intervention's effectiveness on care utilisation for common childhood illnesses.

Methods We included a representative sample of 5773 households with 2874 under-five children at baseline (December 2016 to February 2017) and 10788 households and 5639 under-five children at endline surveys (December 2018 to February 2019) in intervention and comparison areas. Health facilities were also included. We assessed the effect of the intervention using difference-indifferences analyses.

Results There were 31 intervention activities; many were one-off and implemented late. In eight districts, activities were interrupted for 4 months. Care-seeking for any illness in the 2 weeks before the survey for children aged 2-59 months at baseline was $58 \%(95 \% \mathrm{Cl} 47$ to 68$)$ in intervention and $49 \%(95 \% \mathrm{Cl} 39$ to 60$)$ in comparison areas. At end-line it was $39 \%(95 \% \mathrm{Cl} 32$ to 45$)$ in intervention and $34 \%(95 \% \mathrm{Cl} 27$ to 41$)$ in comparison areas (difference-in-differences -4 percentage points, adjusted $\mathrm{OR} 0.49,95 \% \mathrm{Cl} 0.12$ to 1.95 ). The intervention neither had an effect on care-seeking among sick neonates, nor on household participation in community

\section{Strengths and limitations of this study}

- We conducted a rigorous effectiveness evaluation of an intervention to increase the utilisation of services for sick under-five children using baseline (December 2016 to February 2017) and endline (December 2018 to February 2019) surveys, in intervention and comparison areas located in 56 districts across four regions of Ethiopia.

- Data were triangulated with service utilisation records from health posts and health centres, which supported the household-level findings of no change in service utilisation as a result of the intervention.

- Although only few of the household characteristics differed between intervention and comparison areas over time and had only a marginal influence on the analyses, it is possible that unmeasured confounders might contribute to the observed results.

- At baseline, the overall proportion of reported illness in the last 2 weeks was lower than anticipated, and this was higher at the endline indicating that the difference in the reported proportion of sick children could be due to differences in the interaction and the extent of the probing between data collectors and families when enquiring about childhood illnesses.

- Data collectors were blinded to the allocation, that is, whether the district where they collected data was an intervention or comparison area, indicating that any differential reporting of care utilisation between intervention and comparison areas is, therefore, unlikely. 
engagement forums, supportive supervision of primary care workers, nor on indicators of district accountability for child health services.

Conclusion We found no evidence to suggest that the intervention increased the utilisation of care for sick children. The lack of effect could partly be attributed to the short implementation period of a complex intervention and implementation interruption. Future funding schemes should take into consideration that complex interventions that include behaviour change may need an extended implementation period. Trial registration number ISRCTN12040912.

\section{INTRODUCTION}

In the period 1990-2015, Ethiopia reduced under-five mortality by $67 \% .{ }^{1}$ The Ethiopian Demographic and Health Surveys (DHS) showed infant mortality rates at 77, 48 and 43 deaths per 1000 live births, in 2005, 2016 and 2019 reports, respectively. ${ }^{2-4}$ Between 2005 and 2016, neonatal mortality decreased from 39 to 29 deaths per 1000 live births, but in 2019 had stagnated at around 30. Both health system expansion and socioeconomic improvements have contributed to the reductions in mortality. ${ }^{5}$

In 2003, the Ethiopian government launched the health extension programme to increase primary care services. ${ }^{1}$ Salaried female workers, known as health extension workers (HEWs), were trained to provide basic community-based services. Two HEWs at the health post serve a population of approximately 5000 people. Five health posts and their referral health centre and primary hospital comprise a primary healthcare unit. The health extension programme has 17 packages that fall under four broad areas: family health services, disease prevention and control, hygiene and environmental sanitation and health education and communication. ${ }^{1}$ The HEWs are supported by the Women's Development Army leaders, a network of volunteer women established in 2011, who, along with other development goals, promote healthy practices in the community. ${ }^{67}$

In 2010, the integrated community case management (iCCM) strategy was launched, allowing HEWs to manage common childhood illnesses in children under 5 years of age, including pneumonia, malaria and diarrhoea. ${ }^{8}$ In 2013, the community-based newborn care (CBNC) was integrated into the health extension programme. ${ }^{9}$ This initiative enabled HEWs to provide antibiotics for young infants with symptoms of possible serious bacterial infection when a referral was not possible.

Care-seeking for sick under-five children has remained low. ${ }^{10}$ In $2016,46 \%$ of children with diarrhoeal diseases received oral rehydration therapy, and one-third of children with suspected pneumonia were taken to an appropriate care provider. $^{2}$

Several barriers to the utilisation of services for childhood illnesses have been identified. The perceived quality of services provided by the HEWs, financial constraints and preference for alternative care providers affected the utilisation of child health services. ${ }^{11-13}$ Service uptake was associated with maternal education levels, parents' knowledge of danger signs, the type of illness, local beliefs and the need for permission from family decision-makers to seek care. ${ }^{12}$ 14-16 Health post closure, absence of HEWs, lack of essential drugs and supplies, distance and the quality of services also contributed to the low service utilisation. ${ }^{12} 141718$ Insufficient supervision and lack of government accountability and ownership of child health services also constituted barriers. ${ }^{8}$

Based on a barriers-and-facilitators study, the Ethiopian Government initiated the Optimising the Health Extension Programme (OHEP) intervention. ${ }^{19}$ OHEP was based on the following hypotheses: community engagement activities would enhance caregiver knowledge and household practices. Furthermore, capacity strengthening would improve the availability of quality services in the CBNC and iCCM programmes, and promotion of district-level ownership and accountability would integrate these services into the district-level planning and budgeting. These different components together would hypothetically lead to increased utilisation of CBNC and iCCM services.

This study aimed to assess the extent to which the OHEP intervention increased care-seeking for children under the age of 5 years, by comparing changes over time in intervention and comparison areas. Secondary outcomes included treatment of sick children with diarrhoea, suspected pneumonia or neonatal sepsis.

\section{METHODS \\ Study setting}

The Ethiopian Government initiated the OHEP intervention in 26 districts of Amhara, Southern Nation, Nationalities and Peoples, Oromia and Tigray regions with an approximate population of 3.5 million (figure 1 ). Intervention districts were selected by the government of Ethiopia and implementing partners for having both a relatively low utilisation of primary child health services and the availability and ability of partners to support implementation. The implementers were four nongovernmental organisations (PATH, UNICEF, Save the Children and Last 10 Kilometres/John Snow Inc.). The intervention started in 2016 and lasted for a duration of 2.5 years and had three components: 1) community engagement, 2) primary care level capacity building and 3) ownership and accountability of child health services at the district level. The intervention activities under these components, along with the underlying assumptions, intermediate indicators and outcomes are detailed in table 1 .

\section{Study design}

The protocol for the evaluation of the OHEP implementation has been published. ${ }^{20}$ This study was based on a plausibility design with 26 intervention and 26 comparison districts (woredas) in four regions of Ethiopia. The baseline survey was conducted from December 2016 to February 2017 and the endline survey from December 2018 to February 2019 (figure 1). The surveys were 

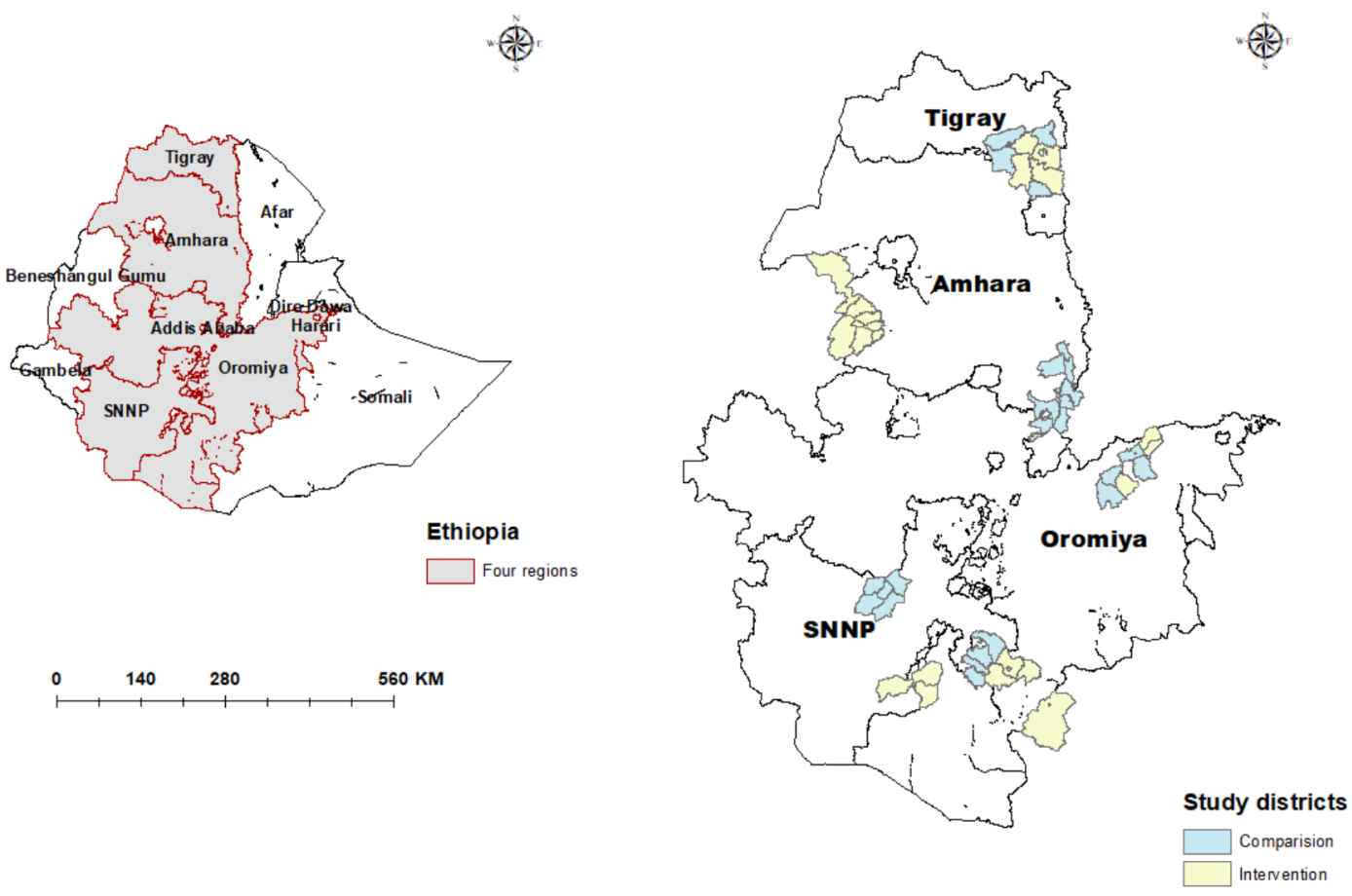

Figure 1 Map of Ethiopia showing all regions (left) and the intervention and comparison districts within the four study regions (right).

conducted by the London School of Hygiene and Tropical Medicine and Ethiopian Public Health Institute along with representatives from Gondar, Jimma, Mekelle and Hawassa Universities.

\section{Sample}

Intervention districts had a low coverage of maternal, newborn, and child health indicators. Comparison districts were selected by the Regional Health Bureaus to be similar to the size of the population, the burden of diseases, number of primary healthcare units, health service coverage, length of iCCM and CBNC service delivery and absence of partners implementing other demand generation activities.

We used a two-stage stratified cluster sampling to select a representative sample of households within intervention and comparison areas. In the first stage, a list of all enumeration areas of the study districts was obtained based on the 2007 Ethiopian Housing and Population Census. Two hundred enumeration areas (clusters) were selected with probability proportional to the size of the district. Each cluster served as the primary sampling unit. Within clusters, households were selected by systematic random sampling. The Women's Development Army leaders, HEWs, health posts, health centres with staff and woreda health offices serving the selected clusters were also surveyed.

The sample size was calculated to measure changes with adequate power in a fixed number of percentage points of key indicators between intervention and comparison areas at baseline and endline. Based on the Ethiopian
DHS data, a cross-sectional survey of 3000 households in 100 intervention and 100 comparison clusters was expected to find 1747 children under the age of 5 years in each arm. ${ }^{21}$ A Tanzanian childhood study found that $50 \%$ of under-fives had an illness in the 2 weeks before the survey. ${ }^{22}$ The current research assumed more conservatively $30 \%$ of children 2-59 months to have had any illness during the 2 weeks before the interview. This sample size of 3000 households per group with $90 \%$ completeness and a design effect of 1.3 would give $80 \%$ power to detect differences of 10-20 percentage points across a range of child health indicators (5\% significance level). The baseline survey found fewer than the expected number of sick children in the 2 weeks before the survey. As a result, the household sample size for the endline survey was doubled. We used the baseline list of households to select 66 households randomly in each enumeration area.

\section{Measurements}

For every selected household, we interviewed the household head, listed residents and collected sociodemographic characteristics. The interviews included caregivers of children aged 2-59 months to assess their knowledge of childhood illnesses and care-seeking for sick under-five children in the 2 weeks before the survey. Furthermore, women of reproductive age (13-49 years) were interviewed to identify births in the 12 months before the survey, with additional questions on careseeking for illness in the neonatal period. Up to three visits were made to each participant to ensure the study reached its target sample size. 
Table 1 Optimising the Health Extension Programme intervention implemented in 26 districts of Ethiopia, the assumptions and the expected intermediate indicators and outcomes

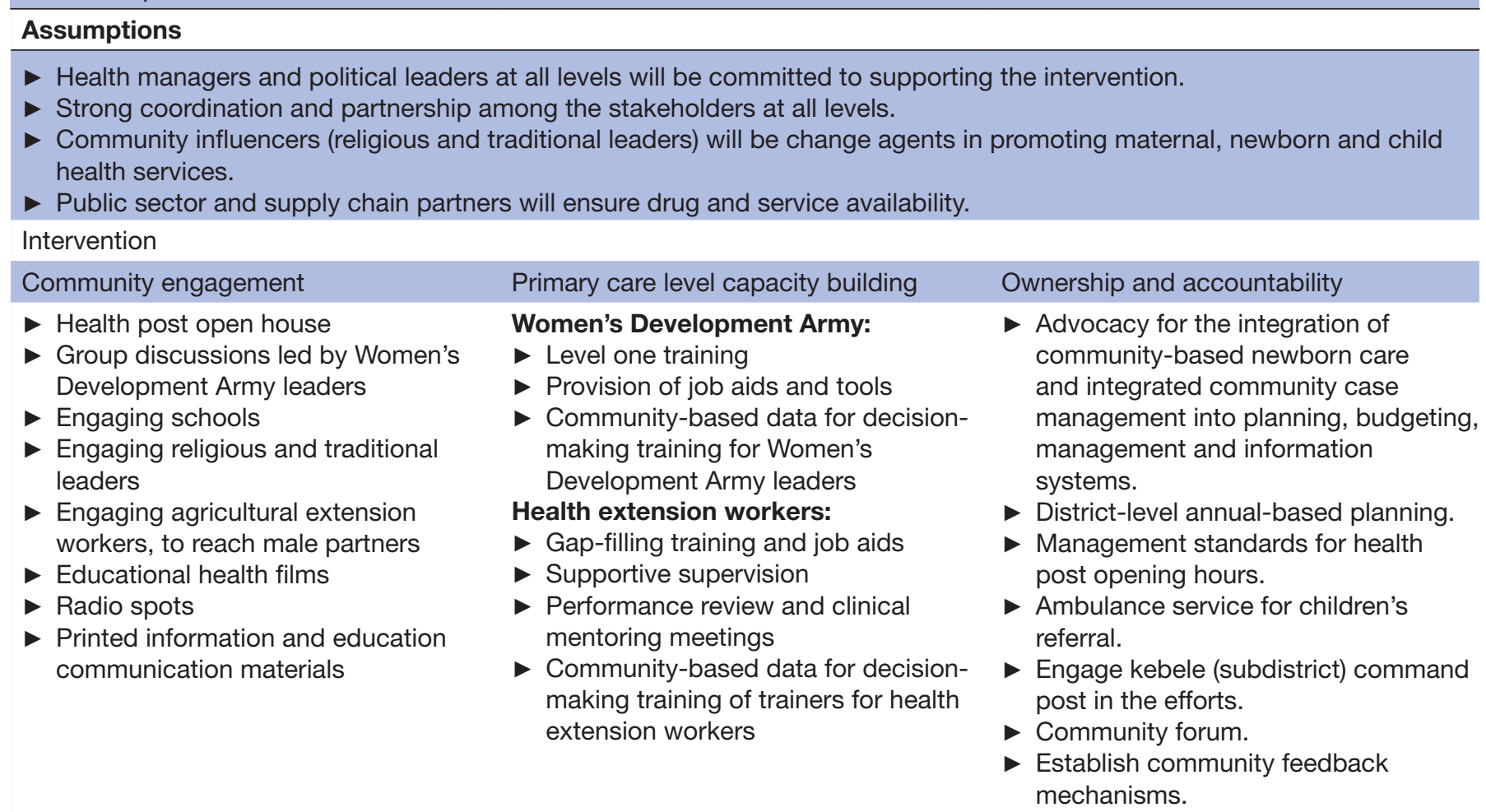

Intermediate indicators

Caregivers knowledge, practices and community participation on matters relating to child health
Facility readiness in terms of medicine, equipment and supplies as well as health worker training and supervision necessary to provide child health services
Planning and monitoring of child health services in the district health system (availability of ambulance, communitybased newborn care and integrated community case management indicators and standardised operational hours for health posts).

\section{Outcomes}

\section{Primary outcome}

Service utilisation from an appropriate provider for sick children between the ages of 2 and 59 months.

2. Secondary outcomes

Appropriate treatment for diarrhoea and pneumonia.

Care-seeking for infants who were ill in the neonatal period.

Appropriate treatment for possible serious bacterial infection in the neonatal period.

The health facility questionnaires assessed the infrastructure, equipment, supplies and staff available on the day of the survey. Also, data were collected from facility registers on services provided to sick children at health posts and health centres in the 3 months preceding the survey. The health centre staff, HEWs and Women's Development Army leader modules covered their background, knowledge, training in the last 12 months, supervision in the previous 6 months and the services they provided in the last 3 months. Interviewers collected information at the district health office on demography and characteristics that might affect services for under-five children.

The questions and content of each survey module were based on existing large-scale survey tools and the authors' previous evaluation of the $\mathrm{iCCM}$ and $\mathrm{CBNC}$ programmes. ${ }^{22} 23$ All questionnaires were translated into three local languages (Amharic, Oromifa and Tigrigna), pretested and revised. Data collectors and supervisors were trained over 10 days, including field training before the start of data collection. They were not provided information on whether a district was an intervention or comparison area.

Data were collected on personal digital assistants (Companion Touch 8), and tablets (Toshiba and Hewlett Packard) programmed with CSPro 6.3 at baseline and CSPro 7.1 at the endline. Data collectors sent encrypted data from the field to the password-protected server at the Ethiopian Public Health Institute. Data managers conducted quality checks and feedback to field teams. Data were cleaned, checked for errors, including 
consistency and completeness. Since OHEP was a community and health system level intervention, a data monitoring committee was not deemed necessary.

\section{Outcomes}

The primary outcome was the proportion of children aged 2-59 months who were reported to have had any illness in the 2 weeks before the survey for whom advice or treatment was sought from an appropriate provider (health post, health centre, hospital and private clinic).

Secondary outcomes included: 1) the proportion of sick children aged 2-59 months who were reported to have received appropriate treatment for diarrhoea (oral rehydration solution (ORS) with or without zinc tablets) and possible pneumonia (antibiotics), 2) the proportion of infants born in the 12 months before the survey who were reported to have had any illness in the first 28 days of life for whom advice or treatment was sought from an appropriate provider and 3) the proportion of infants born in the 12 months before the survey who received adequate treatment for suspected neonatal sepsis (antibiotics). Since malaria was not a common illness in the study areas at the time of the surveys, the assessment of appropriate treatment for this illness was excluded. Additionally, the registers for children aged 0-59 days and 2-59 months were reviewed to assess the median number of children seeking care at health centres and health posts in the 3 months before the surveys.

We also evaluated intermediate indicators that included, at the community level, the proportion of caregivers that knew signs of illness in children and the proportion that cited appropriate action to be taken for a sick child under 5 years of age. We also assessed the proportion of caregivers that reported receiving health messages on common childhood illnesses and those attending community meetings to discuss maternal, newborn and child health issues. At the health system level, we assessed the proportion of HEWs that had received training and the proportion that had attended performance review and clinical mentoring meetings. We also evaluated the proportion of health centres and health posts that had received supervision and the proportion that had the necessary equipment, supplies and drugs for the provision of child health services. District-level ownership and accountability for child health programmes were reflected in the proportion of districts that had ICCM and CBNC scorecards. These cards were programme management tools for setting targets and monitoring performance. Information was also collected on the average number of ambulances available in districts to transport sick underfive children and whether there were standardised hours of operation for health posts.

\section{Analyses}

Descriptive analysis of baseline and endline characteristics in intervention and comparison areas was conducted at the household, caregiver, child, health facility and district levels. Categorical variables were summarised using percentages with 95\% CIs. We used means, with SEs, or medians, with IQRs, to summarise continuous variables.

At the district level, the demographic and health systemlevel characteristics were examined. For households, the characteristics of mothers or caregivers of children aged 2-59 months, and women who had a delivery in the 12 months before the survey were assessed. Distribution of age, religion, education, self-reported distance to the nearest health post and socioeconomic status was analysed in intervention and comparison areas at baseline and endline surveys. Similar assessments were done for the distribution of age and sex among children 2-59 months of age and infants born during the 12 months before the survey. Household socioeconomic status was captured by asset ownership, access to utilities and household characteristics. These were aggregated into a single wealth index score using principal component analysis. ${ }^{24}$ The household aggregated scores were grouped into wealth quintiles, where quintile 1 represented the poorest fifth of the households, and quintile 5 represented the least poor fifth. A linear or logistic regression model was fitted, depending on the variable type, to assess if there were any differences between intervention and comparison areas that changed over time. A variable was considered a potential confounder if the differences between intervention and comparison areas showed a statistically significant $(\mathrm{p}<0.05)$ change over time.

Caregivers' knowledge, practice and community participation relating to child health were assessed. Furthermore, the health system level factors associated with child health services, including training and supervision of health workers providing under-five services, and the observed availability of infrastructure, equipment, supplies and drugs for the treatment of childhood illnesses at health posts and health centres were assessed.

Using data from facility registers, we also compared the median number of young infants and children 2-59 months of age who received care in the 3 months before the survey in intervention and comparison areas at baseline and endline. We analysed differences between intervention and comparison areas over time using quantile regression analysis.

Difference-in-differences analyses were used to estimate the effect of the OHEP intervention on care-seeking for sick under-five children. Binary outcome indicators were used to capture whether a sick child had sought care or received treatment. The key independent variable for the outcomes of this study was whether the child lived in the OHEP intervention or comparison area. A model was then created that included an interaction term for the timing of the survey (baseline or endline) and the survey area (OHEP intervention or comparison area). This model allowed for the calculation of the odds of care-seeking or treatment for under-five children in intervention areas as compared with comparison areas, accounting for any differences between baseline and endline survey areas, with adjustment for the cluster sampling and identified 
confounding factors. The Stata V.13 (StataCorp, College Station, Texas, USA) svy commands were used to adjust for clustering. The assessment used a blinded analysis. The code identifying the intervention and comparison areas were revealed after the analysis and interpretations were completed.

\section{Patient and public involvement}

Patient and/or the public were not involved in the design or conduct, or reporting or dissemination plans of this research.

\section{RESULTS}

The OHEP intervention started in some districts in 2016 and was fully operational from the start of 2017 until October 2018. A process evaluation of the implementation will be reported elsewhere ${ }^{25}$ and includes an assessment of implementation fidelity as well as qualitative results on successes and challenges of the implementation. Briefly, a majority of the activities were one-off, assuming that HEWs would catalyse these activities in the communities. The fidelity of the 31 activities varied by district and over time. Many activities were delayed to the last year. In eight of the districts, implementation activities were interrupted 4 months for administrative reasons. Civil unrest in some of the districts had an impact on health services.

Out of the 200 clusters eligible, six intervention clusters were excluded at baseline due to civil unrest and, therefore, not included in the endline survey (figure 2). At endline, a further three intervention clusters and ten comparison clusters were excluded due to civil unrest.

District-level data were not available from five intervention and one comparison districts at baseline, while at endline data were missing from four intervention and two comparison districts (online supplementary table S1). The demographic and health systems characteristics of intervention and comparison districts at baseline and endline surveys were similar. The study districts had an average population size of 130000 inhabitants, with $23 \%$ being women aged 15-49 years, $20 \%$ being children below the age of 5 years. The average household size was 4.6 persons. One-third of the districts had a hospital. There were, on average, five health centres per district and five health posts under each health centre. At the time of the baseline survey, there were one to two ambulances available on average in the district for transporting sick children, while this had increased to two to three at the time of the endline survey. There were also some increases in staffing; health officers at the health centres increased from 2 to 2.5, midwives at health centres from 2.5 to $>3$ and the number of HEWs increased from an average slightly above two per health post to almost 3 . These characteristics were similar across intervention and comparison districts. At the time of the baseline survey, CBNC and iCCM indicators were included in the scorecards of $79 \%$ of intervention and over $90 \%$ of comparison districts. At the endline, over $90 \%$ of all districts had iCCM and CBNC indicators in their scorecards.

The distribution of study participants by age, education and socioeconomic status across intervention and comparison areas showed no evidence of a change over time. There was some evidence that the proportion of Orthodox Christians changed over time, as did the reported distance to the nearest health post. Both were included as confounders in the analysis of the primary outcome. The distribution of sex and age of under-five children remained similar in the study areas over time (table 2). The characteristics of women who had delivered in the 12 months before the survey showed no evidence of change over time. Young infant age distribution changed, which was included as a potential confounder in the analyses (table 3 ).

There was no association between the intervention and child health messages the caregivers had received or attendance at community health-related meetings (online supplementary table S2). Between baseline and endline, caregivers' unprompted knowledge on sick newborn danger signs, such as limited or no movement and skin pustules, showed some increase in intervention areas as compared with comparison areas over time (online supplementary table S3). At baseline and endline, over four-fifths of the caregivers in intervention as well as comparison areas said they would take their child to the health centre for a range of childhood illnesses, while approximately one-fifth said they would go to a health post (online supplementary table S4).

Two or more HEWs were available in most health posts without association to the intervention $(\mathrm{p}=0.55$ in difference-in-differences analysis) (online supplementary table S5). Most health posts were open 5 days a week without any association with the intervention $(p=0.99$ in difference-in-differences analysis). The proportion of health posts that posted their operational days and hours decreased in both areas over time.

The proportion of HEWs trained in iCCM and CBNC remained similar at baseline and endline in intervention and comparison areas (table 4). Maternal, newborn and child health orientation for Women's Development Army leaders decreased slightly in intervention areas and had a minor increase in comparison areas ( $\mathrm{p}=0.34$ in differencein-differences analysis).

At baseline, approximately two-thirds of health centre staff in the intervention and comparison areas reported receiving a supervisory visit in the last 3 months; this remained similar at endline (online supplementary table S6). Over half of all the surveyed HEWs at baseline and endline reported receiving a supervisory visit in the last month. Approximately half in both areas and at both time points reported attending a performance review and clinical mentoring meeting in the 6 months before the survey. One in six Women's Development Army leaders reported meeting with HEWs and other leaders in the 3 months prior to the survey in intervention and comparison areas at baseline and remained similar over time. 


\begin{tabular}{|c|c|c|c|c|c|c|c|}
\hline \multirow{3}{*}{ 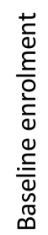 } & \multicolumn{7}{|c|}{200 clusters eligible for study } \\
\hline & & \multicolumn{2}{|c|}{$\begin{array}{l}\text { Excluded } 6 \text { intervention clusters due } \\
\text { to civil unrest }\end{array}$} & 4 & \multicolumn{3}{|c|}{ 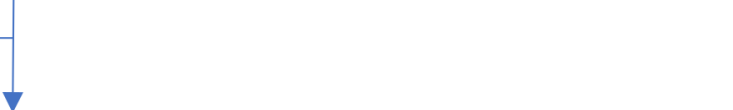 } \\
\hline & \multicolumn{7}{|c|}{194 study clusters } \\
\hline \multirow{11}{*}{ 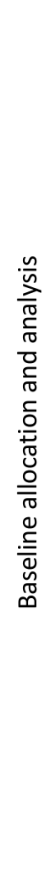 } & \multicolumn{4}{|c|}{$\nabla$} & \multicolumn{3}{|r|}{$\nabla$} \\
\hline & \multicolumn{4}{|c|}{ Intervention: 93 clusters } & \multicolumn{3}{|c|}{ Comparison: 101 clusters } \\
\hline & $\begin{array}{l}\text { Households } \\
\text { to be visited } \\
n=2,790\end{array}$ & $\rightarrow$ & \multicolumn{2}{|l|}{$\begin{array}{l}\text { Excluded } \\
\text { - No one available } n=22 \\
\text { - Missing information } n=11\end{array}$} & $\begin{array}{l}\text { Households to } \\
\text { be visited } \\
n=3,030\end{array}$ & $\rightarrow$ & $\begin{array}{l}\text { Excluded } \\
\text { - No one available } n=14\end{array}$ \\
\hline & \multicolumn{4}{|l|}{ 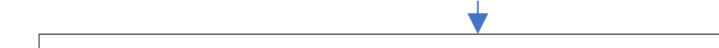 } & \multicolumn{3}{|r|}{$\downarrow$} \\
\hline & \multicolumn{4}{|c|}{ Households included $n=2,757$} & \multicolumn{3}{|c|}{ Households included $n=3,016$} \\
\hline & $\begin{array}{l}\text { Children 2-59 } \\
\text { months listed } \\
\mathrm{n}=1525\end{array}$ & \multicolumn{3}{|c|}{$\rightarrow \begin{array}{l}\text { Excluded } \\
\bullet \text { Missing morbidity information } n=91\end{array}$} & $\begin{array}{l}\text { Children 2-59 } \\
\text { months listed } \\
\mathrm{n}=1471\end{array}$ & $\rightarrow$ & $\begin{array}{l}\text { Excluded } \\
\text { - Missing morbidity information } \mathrm{n}=31\end{array}$ \\
\hline & \multicolumn{4}{|c|}{$\downarrow$} & & & $\nabla$ \\
\hline & \multicolumn{4}{|c|}{$\begin{array}{r}\text { Under-5 children included } n=1,434 \\
- \text { Illness in last } 2 \text { weeks } n=88\end{array}$} & \multicolumn{3}{|c|}{$\begin{array}{c}\text { Under- } 5 \text { children included } n=1,440 \\
- \text { Illness in last } 2 \text { weeks } n=79\end{array}$} \\
\hline & $\begin{array}{l}\text { Women } 13- \\
49 \text { years } \\
\text { listed } \\
n=3,339\end{array}$ & $\rightarrow$ & \multicolumn{2}{|c|}{$\begin{array}{l}\text { Women } 13-49 \text { years excluded } \\
\text { - Travelled away }=88 \\
\text { - Sick } / \text { not present } / \text { missing }=40 \\
\text { - Not pregnant in past } 2 \text { years } n=2880\end{array}$} & $\begin{array}{l}\text { Women } 13- \\
49 \text { years } \\
\text { listed } \\
n=3,307\end{array}$ & \multirow{2}{*}{\multicolumn{2}{|c|}{$\begin{array}{l}\text { Women } 13-49 \text { years excluded } \\
\text { - Travelled away } n=49 \\
\text { - Sick/not present/missing } n=22 \\
\text { - Not pregnant in past } 2 \text { years } n=2905 \\
\downarrow\end{array}$}} \\
\hline & & & $\downarrow$ & & & & \\
\hline & \multicolumn{4}{|c|}{$\begin{array}{l}\text { Women with a birth in last } 12 \text { months included } n=331 \\
\text { - Infants sick in the first month of life } n=47\end{array}$} & \multicolumn{3}{|c|}{$\begin{array}{l}\text { Women with a birth in last } 12 \text { months included } n=331 \\
- \text { Infants sick in the first month of life } n=18\end{array}$} \\
\hline \multirow{3}{*}{ 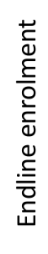 } & & & & 4 cluster & eligible for study & & \\
\hline & & $\begin{array}{l}\text { Exclu } \\
\text { to civ }\end{array}$ & $\begin{array}{l}\text { Ided } 3 \text { intervention clusters due } \\
\text { il unrest }\end{array}$ & & $\begin{array}{l}\text { Exclu } \\
\text { to civ }\end{array}$ & led 10 & $\begin{array}{l}\text { comparison clusters due } \\
\text { est }\end{array}$ \\
\hline & & & & $181 \mathrm{st}$ & dy clusters & & \\
\hline & & & $\nabla$ & & & & $\downarrow$ \\
\hline & Intervention & $: 90 \mathrm{cl}$ & lusters & & Comparison: & 1 clus & sters \\
\hline & $\begin{array}{l}\text { Households } \\
\text { to be visited: } \\
n=5,940\end{array}$ & $\rightarrow$ & $\begin{array}{l}\text { Households excluded } \\
\text { - No one available/refused } n=1 \\
\text { - Missing information } n=424\end{array}$ & & $\begin{array}{l}\text { Households to } \\
\text { be visited: } \\
n=6,006\end{array}$ & $\rightarrow$ & $\begin{array}{l}\text { Households excluded } \\
\text { - No one available/refused } n=308 \\
\text { - Missing information } n=234\end{array}$ \\
\hline$\frac{n}{n}$ & & & $\nabla$ & & & & $\downarrow$ \\
\hline$\frac{\bar{\pi}}{\frac{\pi}{\pi}}$ & Households & includ & $\operatorname{ded} n=5,321$ & & Households & includ & $\operatorname{ded} n=5,464$ \\
\hline 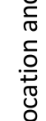 & $\begin{array}{l}\text { Children 2-59 } \\
\text { months listed } \\
n=2960\end{array}$ & $\rightarrow$ & $\begin{array}{l}\text { Excluded } \\
- \text { Missing morbidity information }\end{array}$ & $=28$ & $\begin{array}{l}\text { Children 2-59 } \\
\text { months listed } \\
n=2740\end{array}$ & $\rightarrow$ & $\begin{array}{l}\text { Excluded } \\
\text { - Missing morbidity information } n=33\end{array}$ \\
\hline$\frac{\mathrm{O}}{\bar{\sigma}}$ & & & $\nabla$ & & & & $\downarrow$ \\
\hline 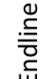 & $\begin{array}{r}\text { Under-5 ch } \\
- \text { IIIn }\end{array}$ & $\begin{array}{l}\text { ildren } \\
\text { ess in }\end{array}$ & $\begin{array}{l}\text { included } n=2,932 \\
\text { last } 2 \text { weeks } n=381\end{array}$ & & $\begin{array}{r}\text { Under-5 c } \\
-\quad \text { IIIne }\end{array}$ & $\begin{array}{l}\text { hildren } \\
\text { ss in la }\end{array}$ & $\begin{array}{l}\text { n included } n=2,707 \\
\text { last } 2 \text { weeks } n=308\end{array}$ \\
\hline & $\begin{array}{l}\text { Women } 13- \\
49 \text { years } \\
\text { listed } \\
n=6,645\end{array}$ & $\rightarrow$ & $\begin{array}{l}\text { Women } 13-49 \text { years excluded } \\
\text { - Travelled away }=94 \\
\text { - Sick/not present } / \text { missing }=125 \\
\text { - Not pregnant in past } 2 \text { years } n=\end{array}$ & 5,944 & $\begin{array}{l}\text { Women } 13- \\
49 \text { years } \\
\text { listed } \\
n=6,295\end{array}$ & $\rightarrow$ & $\begin{array}{l}\text { Women } 13-49 \text { years excluded } \\
\text { - Travelled away } n=302 \\
\text { - Sick/not present } / \text { missing } n=235 \\
\text { - Not pregnant in past } 2 \text { years } n=5,358\end{array}$ \\
\hline & & & $\downarrow$ & & & & $\downarrow$ \\
\hline & $\begin{array}{l}\text { Women witl } \\
\text { - Infants S }\end{array}$ & $\begin{array}{l}\text { a birt } \\
\text { ick in } t\end{array}$ & $\begin{array}{l}\text { th in last } 12 \text { months included } n= \\
\text { the first month of life } n=45\end{array}$ & & $\begin{array}{l}\text { Women with } \\
\text { - Infants sic }\end{array}$ & $\begin{array}{l}\text { birth } \\
\text { in the }\end{array}$ & $\begin{array}{l}h \text { in last } 12 \text { months included } n=400 \\
\text { le first month of life } n=32\end{array}$ \\
\hline
\end{tabular}

Figure 2 Study flow diagram of intervention and comparison categorised by baseline and endline data collection period. 
Table 2 Characteristics of mothers or caregivers of children aged 2-59 months and of their children at baseline (December 2016 to February 2017) and endline surveys (December 2018 to February 2019) in intervention and comparison areas

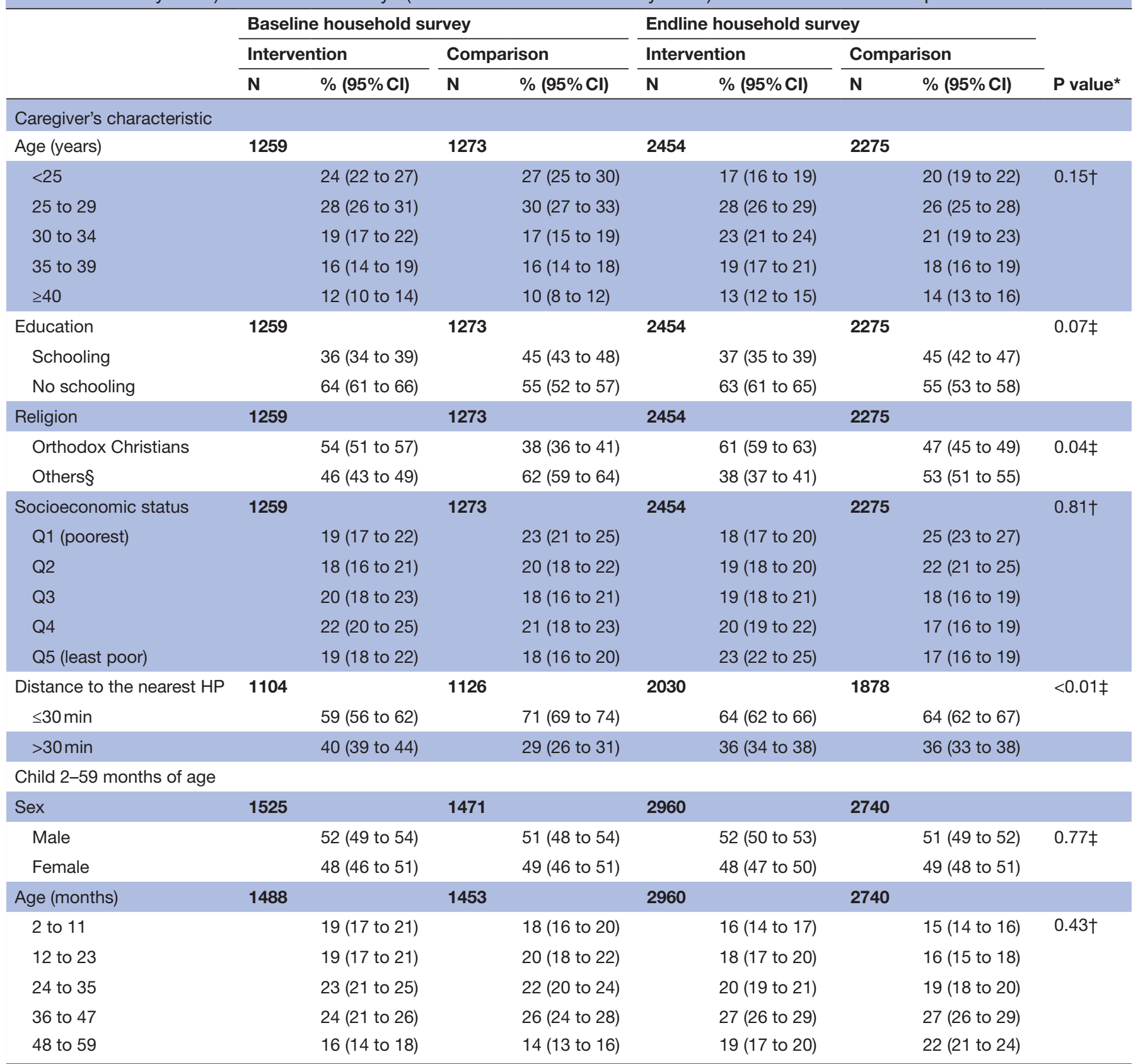

${ }^{*}$ All models were adjusted for clustering.

†P value obtained from linear regression model for the variable to assess whether there was any difference between the groups that changed over time.

$\ddagger \mathrm{P}$ value obtained from logistic regression model for the variable to assess whether there was any difference between the groups that changed over time.

§Includes Catholics, Muslims and Protestants.

Almost all health centres and most health posts had patient toilets (table 5). Water availability on the day of the survey decreased over time in intervention area health centres and health posts, and at endline about three-quarters of health centres and half of the health posts in both study areas had water. Electricity on the day of the survey was available in approximately two-thirds of the health centres and one-fifth of the surveyed health posts at baseline and endline.

At baseline and endline, antibiotics needed to treat sick under-five children were available in most health centres (table 5). At health posts, over three-quarters had amoxicillin. However, gentamicin was not available in over half of the intervention and comparison area health posts 
Table 3 Characteristics of mothers and their children born in the 12 months prior to the survey at baseline (December 2016February 2017) and endline surveys (December 2018-February 2019) in intervention and comparison areas

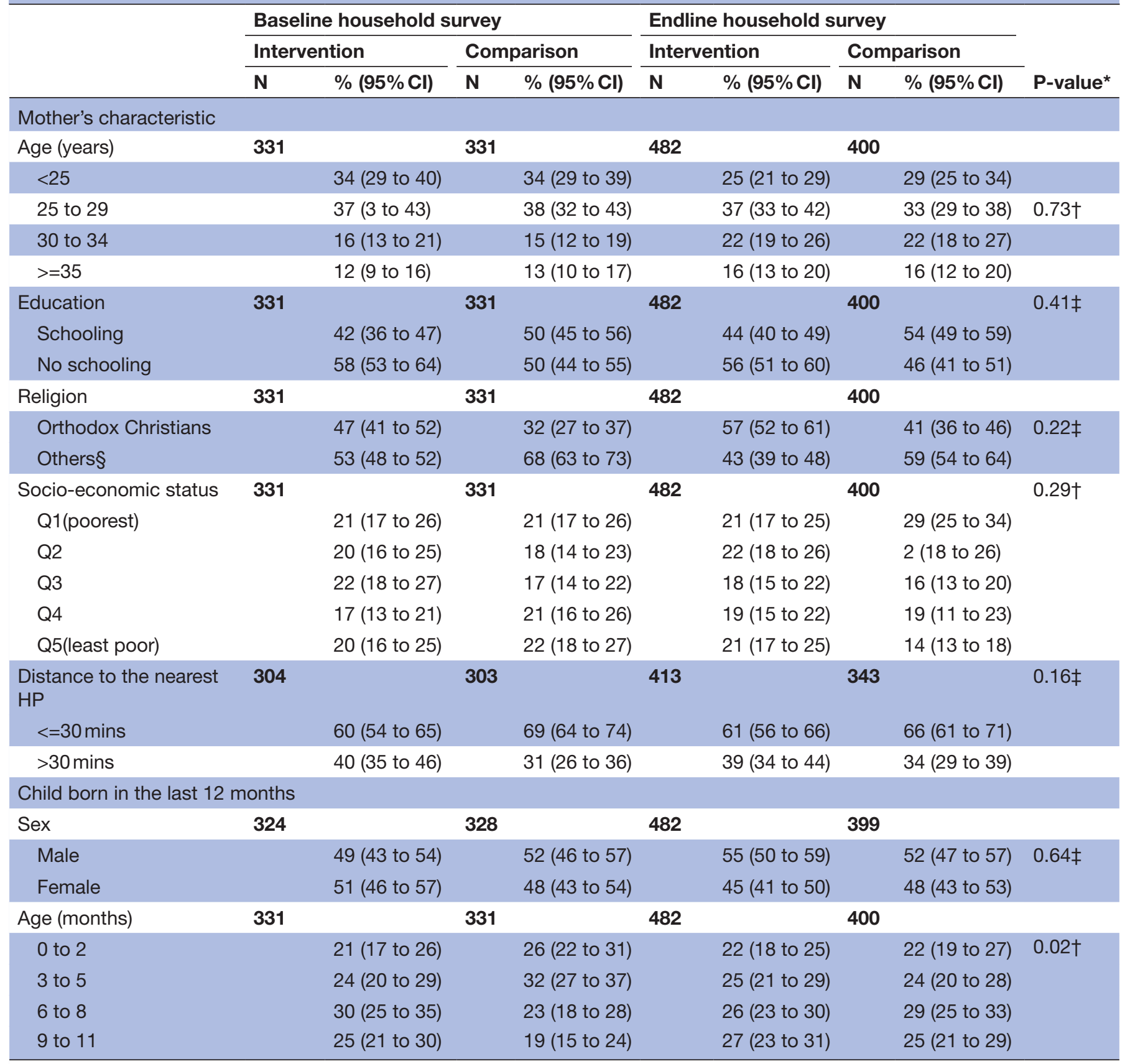

*All models were adjusted for clustering.

†P value obtained from linear regression model for the variable to assess whether there was any difference between the groups that changed over time.

$\ddagger \mathrm{P}$ value obtained from logistic regression model for the variable to assess whether there was any difference between the groups that changed over time.

§Includes Catholics, Muslims and Protestants.

at baseline and endline. ORS and zinc were available in almost all health centres at both time points. Zinc was also available in most health posts at both time points. ORS availability increased over time in both intervention and comparison areas. Almost all health centres had job aids and equipment needed for managing sick under-five children. Health posts lacked some equipment in both study areas at baseline and endline, while most had the necessary job aids at both time points.

The median number of sick young infants registered in intervention area health centres in the quarter before the survey at baseline was five and increased to nine at the endline, while the median remained at three for comparison areas health centres $(\mathrm{p}=0.08)$ (table 6). Intervention 
Table 4 Child health training for health extension workers and Women's Development Army leaders at baseline (December 2016 to February 2017) and endline surveys (December 2018 to February 2019) in intervention and comparison areas

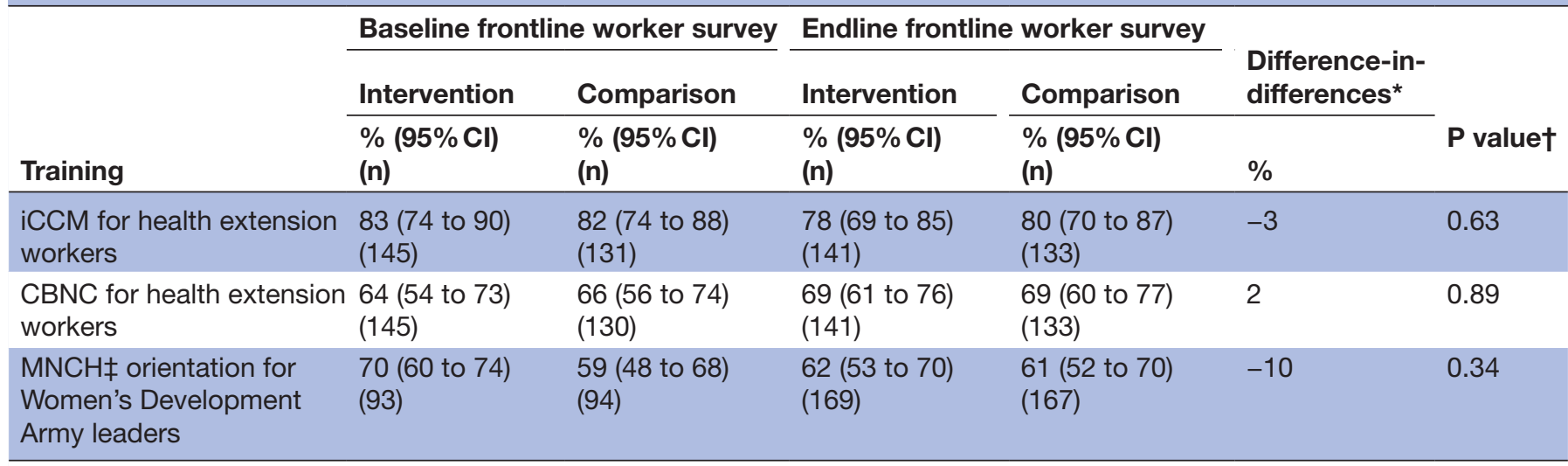

*Difference-in-differences: the difference in the proportion between intervention and comparison areas at endline subtracted from the difference in proportion between intervention and comparison at baseline.

$\dagger P$ value obtained from a logistic regression model for the difference-in-differences analysis. $\ddagger \mathrm{MNCH}$ orientation in the last 12 months.

CBNC, community-based newborn care management training; iCCM, integrated community case management training; $\mathrm{MNCH}$, maternal, newborn and child health.

area health centres at baseline and endline had registered a similar median number of sick children aged 2-59 months (237 vs 232), while comparison area health centres registered fewer ( $149 \mathrm{vs} 128)$ median number of cases $(\mathrm{p}=0.58)$. The median number of sick young infants seen at intervention and comparison area health posts for the quarter before the survey was zero at both baseline and endline. The median number of children aged 2-59 months seen increased from 18 to 22 in intervention areas and decreased from 13 to 10 in comparison areas $(\mathrm{p}=0.22)$.

At baseline, $6 \%$ of intervention and $5 \%$ of comparison area caregivers reported that their children aged 2-59 months had been sick in the 2 weeks before the survey (table 7). At endline, reported illness had increased (13\% and $11 \%)$. Care-seeking for any illness at baseline in intervention areas was $58 \%$ and $49 \%$ in comparison areas, while at endline it was $39 \%$ in intervention areas and $34 \%$ in comparison areas (difference-in-differences -4 percentage points, adjusted OR (AOR) $=0.49$ (95\% CI 0.12 to 1.95) ). The use of ORS with zinc for diarrhoea was $32 \%$ in the intervention areas and $25 \%$ in comparison areas at baseline, while at endline it was to $38 \%$ in intervention areas and $30 \%$ in comparison areas (difference-in-differences +1 , AOR $=0.70$ (95\% CI 0.04 to 13.66)). The use of ORS with or without zinc was higher in intervention than in comparison areas (53\% vs $40 \%)$ at baseline, while at endline it was similar $(50 \%$ vs $53 \%)$ in both areas (difference-in-differences -16 , AOR $=0.29(95 \%$ CI 0.02 to 5.33)). Antibiotic treatment for reported signs and symptoms of possible pneumonia in the intervention areas was higher than in comparison areas at baseline $(67 \%$ vs $56 \%$ ). At endline, it was $62 \%$ in intervention and $69 \%$ in comparison areas (difference-in-differences $-18, \mathrm{AOR}=0.15$ (95\% CI 0.00 to 16.18$)$ ).

Among those that reported illness in the neonatal period, over $70 \%$ reported signs and symptoms of possible sepsis (table 8). At baseline care-seeking for any neonatal illness was higher in intervention as compared with comparison areas $(74 \%$ vs $44 \%)$, while at endline it was lower $(51 \%$ vs $68 \%$ ) in the intervention than in comparison areas (difference-in-differences $-47, \mathrm{AOR}=0.04 \quad$ (95\% CI 0.00 to 0.60$)$ ). Antibiotic treatment among those with possible sepsis at baseline was $51 \%$ in the intervention and $36 \%$ in comparison areas and. At endline, it was $57 \%$ in the intervention and $68 \%$ in comparison areas (difference-indifferences $-26, \mathrm{AOR}=0.19$ (95\% CI 0.02 to 2.42)).

\section{DISCUSSION}

This study found that the OHEP intervention neither had any effect on care-seeking for any illness nor on treatment for diarrhoea or possible pneumonia in children 2-59 months of age. Neither did we find an evidence of an effect on care-seeking for neonatal illness nor on the treatment of possible serious bacterial neonatal infection. These findings were based on household surveys and were supported by results from register reviews at health posts and health centres that showed a low level of service utilisation for sick under-five children at baseline and endline surveys. The intervention did not affect caregivers' participation in community engagement activities. No changes were observed in facility preparedness in health centres and health posts that could be related to the intervention. The health system characteristics at the district level showed small changes, which were not associated with the intervention.

The OHEP intervention took place in selected districts of four regions of Ethiopia. Study population characteristics in intervention and comparison districts were broadly similar. A few of the household characteristics differed between intervention and comparison areas but had a marginal influence on the analyses. It is, however, possible that unmeasured confounders might contribute 


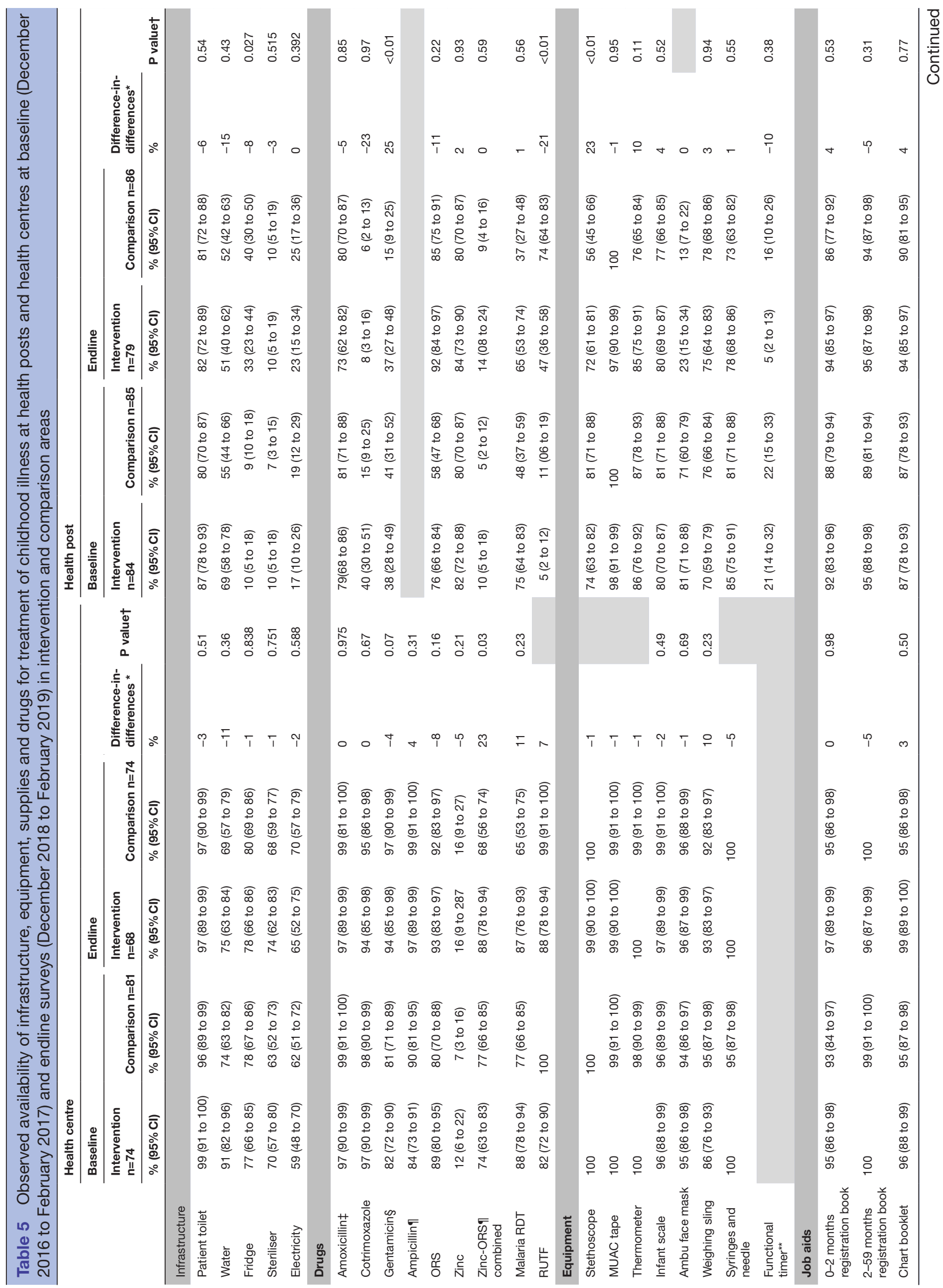

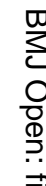

$\stackrel{\overrightarrow{0}}{\stackrel{9}{9}}$

흘 

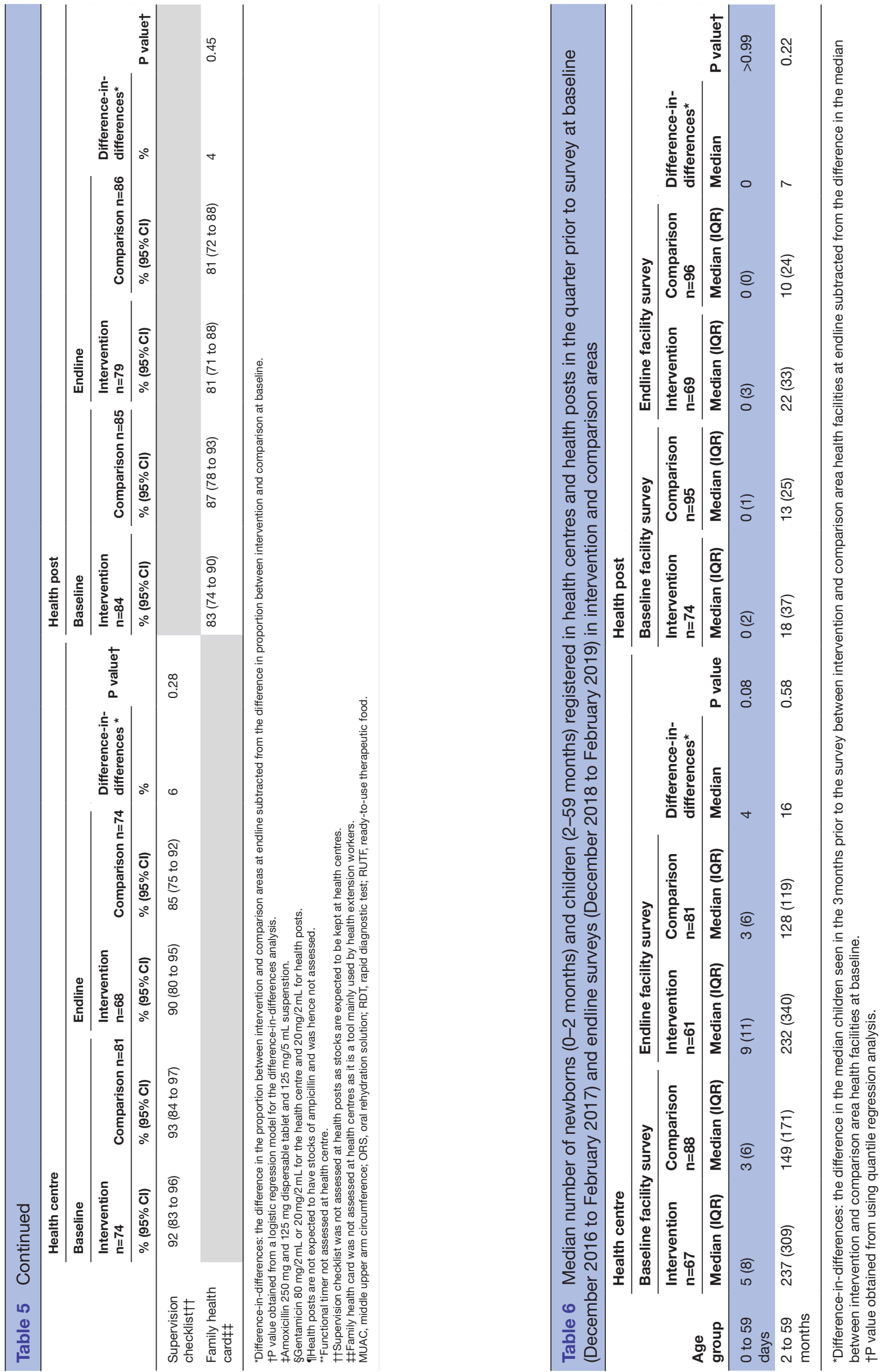

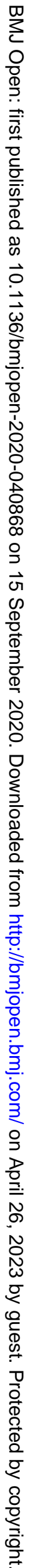




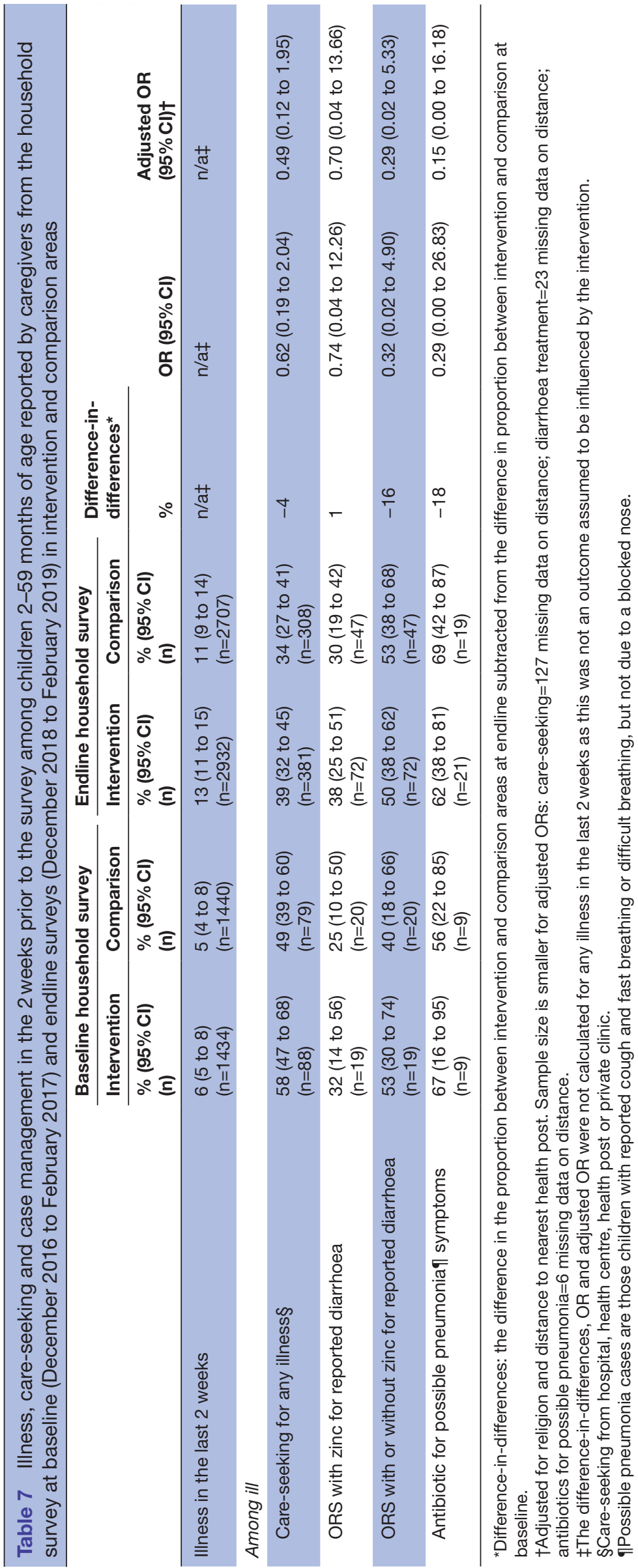

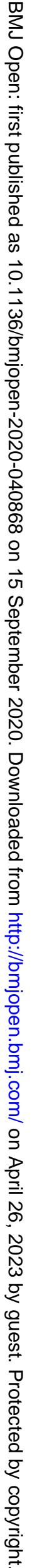



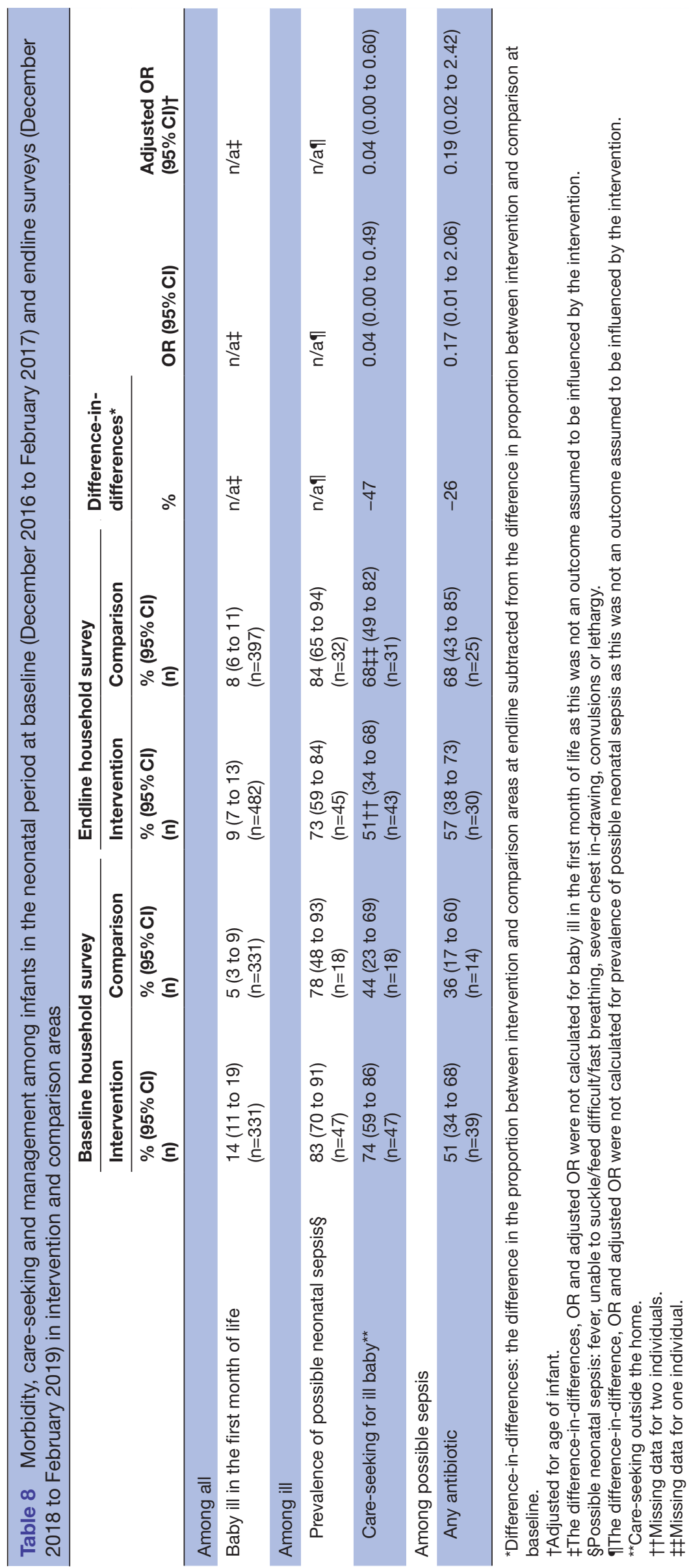
to the observed results. Given that child morbidity has a seasonal variation, both surveys were done during the same months of the year. At baseline, the overall proportion of reported childhood illness in the last 2 weeks was lower than anticipated, and this was higher at the endline. The difference in the reported proportion of sick children could be due to differences in the interaction and the extent of the probing between data collectors and families when enquiring about childhood illnesses. Field interviewers were, however, blinded to the allocation, that is, whether the district where they collected data was an intervention or comparison area. Any differential reporting of care utilisation between intervention and comparison areas is, therefore, unlikely. Service utilisation records from health posts and health centres supported the household-level findings of no change in service utilisation as a result of the intervention.

The three components of the OHEP intervention were based on an analysis of barriers to child health services utilisation in Ethiopia. ${ }^{19}$ As one of the three components, OHEP included several strategies to engage community members, which have been reported to be effective in Ethiopia and elsewhere. ${ }^{26-28}$ Under this intervention, OHEP engaged male agricultural extension workers to reach male partners to address the identified barrier of mothers needing permission from family decision-makers to seek care. The health post open house introduced the newborn and child health services available free of charge to the community. This activity addressed the lack of knowledge of the health post services as well as the perceptions of poor-quality care and costs for seeking care provided by the HEWs. Engaging schoolteachers also aimed to increase the awareness of health post services among parents, via their children. Parents' lack of knowledge of danger signs, preference for alternative care and local beliefs that hindered care seeking for ill children were tackled by involving religious and traditional leaders and communicating behaviour change thorough radio spots and dramas, educational films, family health guide (a low literacy pictorial guide to promote maternal, newborn and child health), posters and brochures. This study found that the OHEP intervention neither improved the reach of health messages on treatment for childhood illnesses to caregivers, nor did it influence their community engagement related to maternal, newborn and child health issues. Most caregivers also indicated that they would rather take their sick child to a health centre than to the health post.

The second component of the OHEP intervention aimed to build capacity through training, supportive supervision and performance review and clinical mentoring to address the identified barrier of poor quality of services provided by HEWs. No changes were observed in the iCCM and CBNC training of HEWs that could be related to the intervention. Training alone may not be sufficient to improve healthcare provider's performance. ${ }^{29}$ Studies conducted in Ethiopia on supportive supervision and performance review and clinical mentorship meetings have also shown that these can be effective means of improving services provided by HEWs. ${ }^{30}$ The OHEP intervention had no effect on the supervision and the performance review and clinical mentoring meetings provided for HEWs. The quality of iCCM services measured at baseline was low, and it is unlikely to have been improved by the training, supervision and infrequent clinical mentoring supported by OHEP. ${ }^{18}$

It is essential to ensure that the actors who are involved in the provision of childhood services are accountable in the development, financing, implementation, and monitoring of the programmes. ${ }^{31}$ The third component of OHEP, district-level ownership and accountability, aimed to address the barrier of health post closure and absence of HEWs by working with the district health offices to standardise and display the health post operational days and hours. Very few health posts displayed this information at the time of the endline survey. Lack of essential drugs and supplies were also identified as barriers and OHEP advocated at the district level to ensure that budget was allocated for their purchase. We found that almost all health centres had ORS, amoxicillin and gentamicin, and nearly all health posts had ORS. Some health posts did not have amoxicillin, and most did not have gentamicin. Compared with another recent Ethiopian study, amoxicillin availability was higher, while the availability of gentamycin was similar. ${ }^{8}$ To address the problem of distance, implementers also advocated that district ambulances be used to transport sick children. Although more ambulances were available at the endline, the increase was not linked to the intervention.

In the current study, approximately half of the ill children 2-59 months of age sought care at baseline, and this decreased to one-third at the endline. Other studies have reported similar and even lower levels of iCCM service uptake in Ethiopia. ${ }^{21432}$ Our baseline result for care-seeking was higher than expected, while the endline proportion follows the gradually increasing trend seen in the DHS surveys. ${ }^{2421}$ Treatment for diarrhoea estimated in this study seemed to follow a plausible upward trend seen across the DHS. The estimated antibiotic treatment for possible pneumonia, which was $<10 \%$ in 2005 and 2011 DHS, was two-thirds in our study. It should be noted that household surveys may not provide a reliable estimate of treatment for possible pneumonia. ${ }^{33}$ It is important to consider the context in which OHEP was implemented to understand the outcomes in this evaluation. One plausible explanation for the lack of observed effect may be the relatively short duration of the intervention. ${ }^{35}$ In comparison with single or multicomponent intervention, complex social and health systems interventions, which have many sequential activities, should not be expected to result in rapid effects on care utilisation. ${ }^{36}$ In some districts, several intervention activities were only fully implemented in the second year, that is, late in the project period. It is also possible that the interaction between different components in a complex intervention within a particular setting might introduce unpredictable effects. ${ }^{37}$ Some intervention activities, such as the health 
post open house, were also one-off efforts that were unlikely to have a sustained effect on service utilisation. The assumptions under which the OHEP intervention was expected to succeed, for example, community influencers becoming change agents to promote child health services, might not have been met. The lack of drugs, particularly for CBNC services, also indicates that the assumption that the public sector and supply chain partners would ensure drug availability was not fully met. In some districts, implementation was also interrupted for several months due to challenges of reaching administrative agreement between implementing and subcontracting partners. Implementation in other districts was also interrupted due to civil unrest, which made it unsafe for project staff to conduct intervention activities. However, it is important to note that civil unrest was present in a similar number of intervention and comparison clusters. Delays were also caused by difficulties in procuring and supplying behaviour change communication tools. Lastly, the OHEP logic framework developed from the analysis of barriers to child health service utilisation in Ethiopia could have benefited from including a behavioural change theory given that the main outcome, care-seeking, required a change in behaviour.

Future interventions should consider other strategies with evidence of improving child health outcomes. Such strategies might include proactive case detection of ill children by Women's Development Army leaders and HEWs through regular door-to-door home visits. ${ }^{38}$ In addition to engaging communities, supporting HEWs through the Women's Development Army leaders can also improve child health outcomes. ${ }^{39}$ A linked study has shown that at while two-thirds of Women's Development Army leaders had monthly contact with HEWs, their overall knowledge on maternal, newborn and child health was low. ${ }^{40}$ While OHEP aimed to improve the competency of Women's Development Army leaders, this aspect of the intervention was poorly implemented. ${ }^{25}$ Improving the Women's Development Army leaders knowledge of danger signs so they can convey health messages regularly to their peers as well as identify and refer ill children to health posts could improve services for under-five children. ${ }^{41}$

\section{CONCLUSION}

This evaluation in four regions of Ethiopia showed that the OHEP intervention did not have an effect on careseeking for sick under-five children. The lack of effect could be attributed to the relatively short period of OHEP implementation, the nature and unmet assumptions of the intervention and implementation interruption. Future funding schemes need to take into consideration that complex interventions with multiple components, including behaviour change, need a more extended implementation period to measure the effectiveness of the programme. This evaluation is linked to an ongoing process evaluation as well as in-depth substudies that address the Women's Development Army leaders' promotion of maternal and child health, quality of care provided by HEWs, equity and geographic distribution of service utilisation that can also offer further explanations to the observed lack of effect. ${ }^{18} 404243$ Given the overall low care-seeking for childhood illnesses in this study continued efforts are needed to strengthen the primary care services for under-five children.

\section{Author affiliations}

${ }^{1}$ Department of Disease Control, Faculty of Infectious and Tropical Diseases, London School of Hygiene and Tropical Medicine, London, UK

${ }^{2}$ Health Systems and Reproductive Health Research Directorate, Ethiopian Public Health Institute, Addis Ababa, Ethiopia

${ }^{3}$ Department of Epidemiology and Biostatistics, Institute of Public Health, College of Medicine and Health Sciences, University of Gondar, Gondar, Ethiopia

${ }^{4}$ Maternal and Child Health Directorate, Ethiopia Ministry of Health, Addis Ababa, Ethiopia

${ }^{5}$ School of Public Health, College of Health Sciences, Mekelle University, Mekelle,

Ethiopia

${ }^{6}$ Department of Population and Family Health, Faculty of Public Health, Jimma University, Jimma, Ethiopia

${ }^{7}$ Department of Health Systems and Policy, Institute of Public Health, College of Medicine and Health Sciences, University of Gondar, Gondar, Ethiopia

${ }^{8}$ College of Medicine and Health Sciences, Hawassa University, Hawassa, Ethiopia

${ }^{9}$ Tigray Regional Health Bureau, Mekelle, Ethiopia

${ }^{10}$ Department of Health Policy and Management, Jimma University, Jimma, Ethiopia

${ }^{11}$ Oromia Regional Health Bureau, Addis Ababa, Ethiopia

${ }^{12}$ Southern Nations, Nationalities \& Peoples Regional Health Bureau, Hawassa, Ethiopia

${ }^{13}$ Institute of Public Health, College of Medicine and Health Sciences, University of Gondar, Gondar, Ethiopia

${ }^{14}$ Amhara Regional Health Bureau, Baher Dar, Ethiopia

${ }^{15}$ Department of Human Nutrition, Institute of Public Health, College of Medicine and Health Sciences, University of Gondar, Gondar, Ethiopia

Acknowledgements The authors would like to thank Lindsay Mangham-Jefferies for drafting the initial protocol and questionnaires for the surveys. The authors would like to thank the field teams that were involved in the data collection as well as the government official that facilitated the administration of the surveys. The authors would also like to thank the study participants who agreed to generously give their time to participate in the study.

Contributors The study was conceived by JS and ETL with inputs from DB, YBO, ADef, AB, AAM, MY, MAW, FW, ADes, FAG, DWD, HB, AT and LP. Contributions to training of data collectors, piloting and supervision during data collection were done by DB, YBO, ADef, LP, ADes, FAG, DWD, HB, ATW, TGetah, TGetac and AH. DW was the data manager. JS, LP, YBO, DB and $A D$ analysed and interpreted the data. DB prepared the first draft of the manuscript with contributions from JS, LP, YBO and $A D$. All authors read and commented on the manuscript and approved the final version.

Funding This project was funded by Bill \& Melinda Gates Foundation (OPP1132551).

Disclaimer The funder had no role in the study design, collection, management, analysis or interpretation of data.

Map disclaimer The depiction of boundaries on this map does not imply the expression of any opinion whatsoever on the part of BMJ (or any member of its group) concerning the legal status of any country, territory, jurisdiction or area or of its authorities. This map is provided without any warranty of any kind, either express or implied.

Competing interests None declared.

Patient consent for publication Not required.

Ethics approval Ethical approvals were obtained from the Ethiopian Public Health Institute (Ethics Ref 613/52) and the London School of Hygiene \& Tropical Medicine (Ethics Ref 16117). Information sheets translated into the three local languages were read out to study participants to obtain their written informed consent.

Provenance and peer review Not commissioned; externally peer reviewed. 
Data availability statement Data are available on reasonable request. Request for data can be made to Della Berhanu (della.berhanu@Ishtm.ac.uk). A data sharing committee has been established. All requests will be reviewed by this committee and if granted, data will be shared without any identifiers.

Open access This is an open access article distributed in accordance with the Creative Commons Attribution 4.0 Unported (CC BY 4.0) license, which permits others to copy, redistribute, remix, transform and build upon this work for any purpose, provided the original work is properly cited, a link to the licence is given, and indication of whether changes were made. See: https://creativecommons.org/ licenses/by/4.0/.

\section{ORCID iDs}

Della Berhanu http://orcid.org/0000-0002-4984-893X

Atkure Defar http://orcid.org/0000-0001-9435-2135

Dawit Wolde Daka http://orcid.org/0000-0001-5465-6345

Lars Åke Persson http://orcid.org/0000-0003-0710-7954

\section{REFERENCES}

1 Assefa Y, Gelaw YA, Hill PS, et al. Community health extension program of Ethiopia, 2003-2018: successes and challenges toward universal coverage for primary healthcare services. Global Health 2019;15:24.

2 Agency CS. Csa) and ICF international. Ethiopia Demogrpahic and health survey 2016. Addis Ababa, Ethiopia and Rockville, Maryland, USA: CSA and ICF, 2016.

3 Ethiopian Public Health Institute (EPHI) and ICF International. Ethiopian Demogrpahic and health survey 2019. Addis Ababa, Ethioia and Rockville, Marlyand, USA: EPHI and ICF, 2019.

4 Central Statistical Agency (CSA) and ICF International. Ethiopian Demogrpahic and health survey 2005. Addis Ababa, Ethiopia and Rockville, Maryland, USA: CSA and ICF, 2006.

5 Ruducha J, Mann C, Singh NS, et al. How Ethiopia achieved millennium development goal 4 through multisectoral interventions: a countdown to 2015 case study. Lancet Glob Health 2017;5:e1142-51.

6 Yitbarek K, Abraham G, Morankar S. Contribution of women's development army to maternal and child health in Ethiopia: a systematic review of evidence. BMJ Open 2019;9:e025937.

7 Damtew ZA, Karim AM, Chekagn CT, et al. Correlates of the women's development army strategy implementation strength with household reproductive, maternal, newborn and child healthcare practices: a cross-sectional study in four regions of Ethiopia. BMC Pregnancy Childbirth 2018;18:373.

8 Hailemariam S, Gebeyehu Y, Loha E, et al. Inadequate management of pneumonia among children in South Ethiopia: findings from descriptive study. BMC Health Serv Res 2019;19:426.

9 Mathewos B, Owen H, Sitrin D, et al. Community-Based interventions for newborns in Ethiopia (combine): cost-effectiveness analysis. Health Policy Plan 2017;32:i21-32.

10 Amouzou A, Hazel E, Shaw B, et al. Effects of the integrated community case management of childhood illness strategy on child mortality in Ethiopia: a cluster randomized trial. Am J Trop Med Hyg 2016;94:596-604.

11 Tefera W, Tesfaye $\mathrm{H}$, Bekele A, et al. Factors influencing the low utilization of curative child health services in Shebedino district, Sidama zone, Ethiopia. Ethiop Med J 2014;52 Suppl 3:109-17.

12 Shaw B, Amouzou A, Miller NP, et al. Access to integrated community case management of childhood illnesses services in rura Ethiopia: a qualitative study of the perspectives and experiences of caregivers. Health Policy Plan 2016;31:656-66.

13 King R, Jackson R, Dietsch E, et al. Barriers and facilitators to accessing skilled birth attendants in afar region, Ethiopia. Midwifery 2015;31:540-6.

14 Shaw B, Amouzou A, Miller NP, et al. Determinants of utilization of health extension workers in the context of scale-up of integrated community case management of childhood illnesses in Ethiopia. Am J Trop Med Hyg 2015;93:636-47.

15 Nigatu SG, Worku AG, Dadi AF. Level of mother's knowledge about neonatal danger signs and associated factors in North West of Ethiopia: a community based study. BMC Res Notes 2015;8:309.

16 Degefie T, Amare Y, Mulligan B. Local understandings of care during delivery and postnatal period to inform home based package of newborn care interventions in rural Ethiopia: a qualitative study. BMC Int Health Hum Rights 2014;14:17.

17 Tilahun $\mathrm{H}$, Fekadu $\mathrm{B}$, Abdisa $\mathrm{H}$, et al. Ethiopia's health extension workers use of work time on duty: time and motion study. Health Policy Plan 2017;32:320-8.
18 Getachew T, Mekonnen S, Yitayal M, et al. Health extension workers diagnostic accuracy for common childhood illnesses in four regions of Ethiopia: a cross-sectional study. Acta Paediatr 2019;108:2100-6.

19 UNICEF and PATH. Literature review on barriers to utilization of health extension services: draft report, 2016.

20 Berhanu D, Okwaraji YB, Belayneh AB, et al. Protocol for the evaluation of a complex intervention aiming at increased utilisation of primary child health services in Ethiopia: a before and after study in intervention and comparison areas. BMC Health Serv Res 2020;20:339.

21 Central Statistical Agency (CSA) and ICF International. Ethiopian Demogrpahic and health survey 2011. Addis Ababa, Ethioia and Calvertn Marlyand, USA: CSA and ICF, 2012.

22 Armstrong Schellenberg JRM, Adam T, Mshinda $\mathrm{H}$, et al. Effectiveness and cost of facility-based integrated management of childhood illness (IMCI) in Tanzania. Lancet 2004;364:1583-94.

23 Berhanu D, Avan BI. Community based newborn care: baseline report summary, Ethiopia Octboer 2014. London: IDEAS London School of Hygiene \& Tropical Medicine, 2014.

24 Vyas S, Kumaranayake L. Constructing socio-economic status indices: how to use principal components analysis. Health Policy Plan 2006;21:459-68.

25 Okwaraji YB, Hill Z, Defar A, et al. Implementation of the 'Optimising the Health Extension Program' Intervention in Ethiopia: A Process Evaluation Using Mixed Methods. Int J Environ Res Public Health 2020;17:5803.

26 Barry D, Frew AH, Mohammed H, et al. The effect of community maternal and newborn health family meetings on type of birth attendant and completeness of maternal and newborn care received during birth and the early postnatal period in rural Ethiopia. $J$ Midwifery Womens Health 2014;59 Suppl 1:S44-54.

27 Tesfaye S, Barry D, Gobezayehu AG, et al. Improving coverage of postnatal care in rural Ethiopia using a community-based, collaborative quality improvement approach. J Midwifery Womens Health 2014;59 Suppl 1:S55-64.

28 World Health Organization and International Initiative for Impact Evaluation. An evidence map of social, behavioural and community engagement interventions for reproductive, maternal, newborn and child health. Geneva: World Health Organization, 2017.

29 Rowe AK, Rowe SY, Peters DH, et al. Effectiveness of strategies to improve health-care provider practices in low-income and middle-income countries: a systematic review. Lancet Glob Health 2018;6:e1163-75.

30 Miller NP, Amouzou A, Hazel E, et al. Assessment of the impact of quality improvement interventions on the quality of sick child care provided by health extension workers in Ethiopia. J Glob Health 2016;6:020404.

31 George A, Rodríguez DC, Rasanathan K, et al. iCCM policy analysis: strategic contributions to understanding its character, design and scale up in sub-Saharan Africa. Health Policy Plan 2015;30 Suppl 2:ii3-11.

32 Amouzou A, Kanyuka M, Hazel E, et al. Independent evaluation of the integrated community case management of childhood illness strategy in Malawi using a national evaluation platform design. Am J Trop Med Hyg 2016;94:574-83.

33 Campbell H, El Arifeen S, Hazir T, et al. Measuring coverage in $\mathrm{MNCH}$ : challenges in monitoring the proportion of young children with pneumonia who receive antibiotic treatment. PLoS Med 2013;10:e1001421.

34 Hazir T, Begum K, El Arifeen S, et al. Measuring coverage in $\mathrm{MNCH}$ : a prospective validation study in Pakistan and Bangladesh on measuring correct treatment of childhood pneumonia. PLoS Med 2013;10:e1001422.

35 Persson Lars Åke, Nga NT, Målqvist M, et al. Effect of facilitation of local Maternal-and-Newborn Stakeholder groups on neonatal mortality: cluster-randomized controlled trial. PLoS Med 2013;10:e1001445.

36 Osrin D, Prost A. Perinatal interventions and survival in resource-poor settings: which work, which don't, which have the jury out? Arch Dis Child 2010:95:1039-46.

37 Hawe P. Lessons from complex interventions to improve health. Annu Rev Public Health 2015;36:307-23

38 Johnson $A D$, Thiero O, Whidden $\mathrm{C}$, et al. Proactive community case management and child survival in periurban Mali. BMJ Glob Health 2018;3:e000634.

39 Freeman PA, Schleiff M, Sacks E, et al. Comprehensive review of the evidence regarding the effectiveness of community-based primary health care in improving maternal, neonatal and child health: 4 . child health findings. J Glob Health 2017;7:010904.

40 Ashebir F, Medhanyie AA, Mulugeta A, et al. Women's development group leaders' promotion of maternal, neonatal and child health 
care in Ethiopia: a cross-sectional study. Glob Health Action 2020;13:1748845.

41 Perry H, Morrow M, Davis T, et al. Care groups II: a summary of the child survival outcomes achieved using volunteer community health workers in resource-constrained settings. Glob Health Sci Pract 2015;3:370-81.
42 Wuneh AD, Medhanyie AA, Bezabih AM, et al. Wealth-based equity in maternal, neonatal, and child health services utilization: a crosssectional study from Ethiopia. Int J Equity Health 2019;18:201.

43 Defar A, Okwaraji YB, Tigabu Z, et al. Geographic differences in maternal and child health care utilization in four Ethiopian regions; a cross-sectional study. Int J Equity Health 2019;18:173. 